\title{
JOURNAL.RU
}

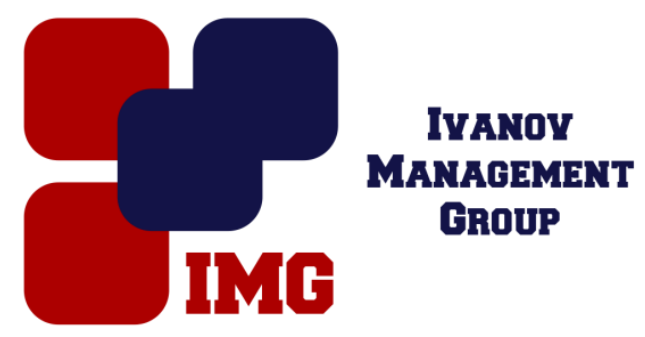

Грихина Н.В., Галкина Ю.Ю. Мичуринский государственный аграрный университет Мичуринск, Россия

doi: $10.18411 / 1 \mathrm{j}-31-05-2017-69$

idsp 000001:1j-31-05-2017-69

\section{Особенности стресс-реактивности организма эмбрионов кур во второй половине инкубации}

\section{Аннотация}

В статье приведены материалы по изучению особенностей стрессреактивности организма эмбрионов кур во второй половине инкубации.

Ключевые слова: инкубация, эмбрионы, стресс-реактивность, тепловое воздействие, гормоны.

Эмбриогенез у птиц протекает вне организма матери и следовательно значительно подвержен действию условий окружающей среды. Как известно, в этот период происходит развитие и интеграция гипоталамо-гипофиз-кортикоадреналовой системы, ответственной за состояние адаптации и стресса. Исследование закономерностей становления адаптационной реакции $\mathrm{y}$ сельскохозяйственных птиц важно для уточнения режимов искусственной инкубации яиц с учетом особенностей биологии развития этого класса позвоночных.

В связи с этим, целью данной работы явилось изучить особенности стрессреактивности организма эмбрионов кур во второй половине инкубации.

Исследования проведены на яйцах кур породы белый леггорн (П-46 ), возраст несушек -310 дней. Использовали инкубаторы «Универсал-55» (37,50 С, относительная влажность- 70 \%). На 12, 14, 16 и 18 сутки инкубации яйца подвергали тепловому воздействию(400 C, 2ч) в термостате. По завершении перегрева яйца помещали обратно в инкубатор. До воздействия, а также через 0 , 
2 и 4 ч после его завершения яйцо вскрывали и из аллантоисной вены отбирали пробы крови.

Определяли концентрацию в сыворотке крови гормонов щитовидной железы - тироксина (Т4) и трийодтиронина(Т3) методом радиоиммунологического анализа. Экспериментальные данные обрабатывали на IBM посредством пакета программ Microsoft Excel.

Результаты исследований по определению концентрации тироксина (T4) и трийодтиронина (Т3) показали, что в процессе эмбрионального развития уровень концентрации этих гормонов увеличивается (табл. 1). Так, если на 12 -е сутки инкубации яиц концентрация Т4 равнялась 5,23 $\pm 0,50$ нмоль/л, то к 18 суткам увеличилась на 2,43 нмоль/л или 45,46\% ( $\mathrm{P}<0,01)$, а концентрация Т3 на 0,66 нмоль/л или $235 \%(\mathrm{P}<0,05)$.

Таблица 1.

Концентращия тироксина (T4) и трийодтиронина (T3) в сыворотке периферической крови эмбрионов, подвергнутых тепловому воздействию

(400 С, 2 ч), нмоль/л

\begin{tabular}{|c|c|c|c|c|c|c|c|c|c|c|c|c|}
\hline \multirow{3}{*}{$\begin{array}{c}\text { Сутк } \\
\text { и } \\
\text { ин } \\
\text { ку- } \\
\text { ба } \\
\text { ции }\end{array}$} & \multicolumn{3}{|c|}{ Состояние покоя } & \multicolumn{9}{|c|}{ Время после окончания воздействия, ч } \\
\hline & & & & \multicolumn{3}{|c|}{0} & \multicolumn{3}{|c|}{2} & \multicolumn{3}{|c|}{4} \\
\hline & $\mathrm{T}_{4}$ & $\mathrm{~T}_{3}$ & $\mathrm{~T}_{3} / \mathrm{T}_{4}$ & $\mathrm{~T}_{4}$ & $\mathrm{~T}_{3}$ & $\mathrm{~T}_{3} / \mathrm{T}_{4}$ & $\mathrm{~T}_{4}$ & $\mathrm{~T}_{3}$ & $\mathrm{~T}_{3} / \mathrm{T}_{4}$ & $\mathrm{~T}_{4}$ & $\mathrm{~T}_{3}$ & $\begin{array}{c}\mathrm{T}_{3} / \mathrm{T} \\
4\end{array}$ \\
\hline 12 & $\begin{array}{c}5,23 \pm \\
0,50\end{array}$ & $\begin{array}{c}0,28 \pm \\
0,07\end{array}$ & 0,05 & $\begin{array}{c}5,83 \pm \\
0,60^{\mathrm{B}}\end{array}$ & $\begin{array}{c}0,35 \pm \\
0,05^{\mathrm{B}}\end{array}$ & 0,06 & $\begin{array}{c}4,23 \pm \\
0,26\end{array}$ & $\begin{array}{c}0,38 \pm \\
0,15\end{array}$ & 0,09 & $\begin{array}{c}5,0 \pm \\
0,0\end{array}$ & $\begin{array}{c}0,34 \\
\pm \\
0,09\end{array}$ & 0,07 \\
\hline 14 & $\begin{array}{c}7,16 \pm \\
2,42\end{array}$ & $\begin{array}{c}0,49 \pm \\
0,06\end{array}$ & 0,07 & $\begin{array}{c}5,40 \pm \\
0,49^{\mathrm{B}}\end{array}$ & $\begin{array}{c}0,34 \pm \\
0,06^{\mathrm{B}}\end{array}$ & 0,06 & $\begin{array}{c}4,83 \pm \\
0,16\end{array}$ & $\begin{array}{c}0,45 \pm \\
0,12\end{array}$ & 0,09 & $\begin{array}{l}4,36 \pm \\
0,37^{\mathrm{c}}\end{array}$ & $\begin{array}{c}0,41 \\
\pm \\
0,24\end{array}$ & 0,09 \\
\hline 16 & $\begin{array}{c}5,33 \pm \\
0,60\end{array}$ & $\begin{array}{c}0,71 \pm \\
0,23\end{array}$ & 0,13 & $\begin{array}{c}4,83 \pm \\
0,16^{\mathrm{B}}\end{array}$ & $\begin{array}{c}0,80 \pm \\
0,05\end{array}$ & $0,17^{\mathrm{B}}$ & $\begin{array}{c}5,73 \pm \\
0,62\end{array}$ & $\begin{array}{c}0,53 \pm \\
0,14\end{array}$ & 0.09 & $\begin{array}{c}5,50 \pm \\
0,57\end{array}$ & $\begin{array}{c}0,83 \\
\pm \\
0,06^{\mathrm{c}}\end{array}$ & $0,15^{\mathrm{c}}$ \\
\hline 18 & $\begin{array}{c}7,66 \pm \\
1,09^{\mathrm{a}}\end{array}$ & $\begin{array}{c}0,94 \pm \\
0,04^{\mathrm{a}}\end{array}$ & $0,12^{\mathrm{a}}$ & $\begin{array}{l}6,56 \pm \\
0,23^{\text {B }}\end{array}$ & $\begin{array}{c}0,68 \pm \\
0,04^{\mathrm{B}}\end{array}$ & 0,10 & $\begin{array}{c}6,23 \pm \\
0,43\end{array}$ & $\begin{array}{c}0,76 \pm \\
0,24\end{array}$ & 0,12 & $\begin{array}{l}7,90 \pm \\
0,45^{\mathrm{c}}\end{array}$ & $\begin{array}{c}1,01 \\
\pm \\
0,21^{\mathrm{c}}\end{array}$ & 0,13 \\
\hline
\end{tabular}

Обращает на себя внимание тот факт, что величина концентрации Т4 в состоянии покоя на 12 и 16 сутки развития находится почти на одном уровне, тогда как на 14 и 18 сутки инкубации значительно увеличивается. Степень увеличения концентрации Т4 в период с 12 по 14 сутки эмбриогенеза меньше таковой в период с 16 по 18 сутки развития, а именно, 36,9\% и 43,7\% соответственно. Величина концентрации Т3 в состоянии покоя в период с 12 по 18 сутки инкубации увеличивается практически прямо пропорционально возрасту эмбрионов. 
Выявлено, что эмбрионы разного возраста неодинаково реагируют на тепловое воздействие. Например, у 12= суточных эмбрионов сразу после такового зарегистрировано увеличение концентрации Т4 и Т3 на 10,3 и 20\% соответственно по сравнению с состоянием покоя. Однако, у 14, 16 и 18 суточных эмбрионов тепловое воздействие обусловило уменьшение концентрации Т4 соответственно на $24,5 \%, 9,4$ и $14,4 \%$ (P< 0,01). Тождественная зависимость зафиксирована и в кинетике концентрации Т3.

Установлено, что на 16 сутки инкубации спустя 2 ч после окончания воздействия, происходит увеличение уровня концентрации Т4 и уменьшение Т3. Тогда как у 12=, 14= и 18= суточных эмбрионов обнаружено обратная зависимость, т.е. уменьшение Т4 и увеличение Т3.

Кроме того, установлено, что спустя 4ч после окончания воздействия у эмбрионов $12=$ и $18=$ суточного возраста происходит увеличение концентрации T4, тогда как у 14= и 16= суточных эмбрионов на этот момент отмечено уменьшение концентрации исследуемого гормона. Следует также отметить, что у $12=$ суточных эмбрионов увеличение концентрации Т4 составило $18,2 \%$, а у $18=$ суточных по сравнению с $12=$ суточными было больше на $8,6 \%$, т.е. равнялась $26,8 \%$.

Следует отметить, что концентрация Т3 спустя 4 ч после окончания воздействия у 12= и 14= суточных эмбрионов по сравнению с таковой у эмбрионов того же возраста, но спустя 2 ч после окончания воздействия, уменьшилась, тогда как у 16= и $18=$ суточных эмбрионов увеличилась. Причем, максимальная степень увеличения выявлена у 16= суточных эмбрионов, она равна $56,6 \%$, а у $18=$ суточных эмбрионов $-32,89 \%$.

Соотношение T3/T4 в ходе эмбриогенезе увеличивалось. Так, на 12 сутки инкубации эта величина составила 0,5 и уже к 18 суткам, увеличившись на 0,07 достигла 0,12 . Максимальное значение соотношения T3/T4 зафиксировано на 16 сутки эмбрионального развития и равнялось 0,13 .

Обнаружено, что $12=$ и 16= суточные эмбрионы по сравнению с 14= и 18= суточными несколько иначе реагируют на тепловое воздействие. Свидетельством этого явилось увеличение значения соотношения Т3/Т4 сразу после окончания воздействия на $20 \%$ и $30,76 \%$ соответственно по сравнению с состояние покоя. На подобное воздействие 14= и 18= суточные эмбрионы реагировали уменьшением данной величины до 0,06 и 0,10 , соответственно. 
Через 2 ч после окончания воздействия у 16=суточных эмбрионов в противоположность $12=, 14=$ и $18=$ суточным зарегистрировано уменьшение величины соотношения Т3/T4 на 0,08 или $47,05 \%$.

Необходимо отметить, что отличие $16=$ суточных эмбрионов от $12=, 14=$ и $18=$ суточных прочно сохраняются и спустя 4 ч после окончания воздействия, т.е. в этот момент исследований у $16=$ суточных эмбрионов выявлено резкое увеличение соотношения T3/T4, а именно на $66,6 \%$ по сравнению с величиной искомого показателя, обнаруженной спустя 2 ч после окончания воздействия.

Таким образом, кинетика гормонов щитовидной железы изменяется в течение второй половины инкубации с возрастом эмбрионов. Установлено, что на тепловое воздействие эмбрионы разного возраста реагируют неодинаково.

1. Белов, А.Д. Клиническая лабораторная диагностика в ветеринарии. М., 1985.

2. Дядичкина, Л.Ф. Инкубация-главное звено в цепи воспроизводства стада. Птицеводство.// Л.Ф. Дядичкина.-2010, 1, с.21-23.

3. Меерсон, Н.И. Адаптация, стресс и профилактика. М., 1981.

4. Методические рекомендации по инкубации яиц с.-х. птицы. Сергиев Посад, 2001.

5. Смолов, С.В. Состояние органов иммунной системы у эмбрионов и цыплят в зависимости от температурных условий инкубации яиц. Автореф. канд. дис. Сергиев Посад, 2002.

6. Щеголев, О.Б. Инкубация яиц и содержание цыплят . Х.: ФЛ-П Стеценко И. И., 2010, $128 \mathrm{c}$. 